Case Report

\title{
Anticoagulation Rationale in an Elderly Patient with Stroke, Cerebral Amyloid Angiopathy, and Antiphospholipid Syndrome: A Case Report
}

\author{
Axel Ferreira ${ }^{1,}{ }^{*}$, Filipa Guimarães ${ }^{2}$, Paulo Simões Coelho ${ }^{1}$
}

1. Neurology Department, Hospital pedro Hispano, ULS Matosinhos, Portugal; E-Mails: axelferr@gmail.com; pauloscoelho@icloud.com

2. Internal Medicine Department, Hospital pedro Hispano, ULS Matosinhos, Portugal; E-Mail: lipaguima@gmail.com

* Correspondence: Axel Ferreira; E-Mail: axelferr@gmail.com

Academic Editor: David G. Smithard

Special Issue: Stroke in Older Adults

OBM Geriatrics

2020, volume 4, issue 4

doi:10.21926/obm.geriatr.2004145
Received: September 29, 2020

Accepted: December 14, 2020

Published: December 24, 2020

\begin{abstract}
We present a case of a 74-year-old woman with deep intracerebral hemorrhage (ICH), probable cerebral amyloid angiopathy (CAA), and probable antiphospholipid syndrome (APS). Due to the high hemorrhagic risk, it was decided not to use anticoagulants. In a period of three months, she had two separate cerebral ischemic events and died of stroke-related complications. The use of oral anticoagulation (OAC) in this patient is neither supported nor contra-indicated by current literature, even though past medical history suggests a very high $\mathrm{ICH}$ recurrence rate, probably contra-indicating the use of OAC.
\end{abstract}

\section{Keywords}

Stroke; anticoagulation; cerebral amyloid angiopathy; antiphospholipid syndrome; cerebral microbleeds

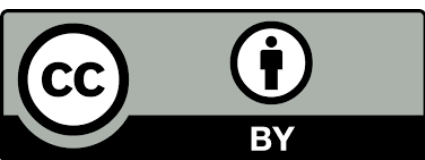

(C) 2020 by the author. This is an open access article distributed under the conditions of the Creative Commons by Attribution License, which permits unrestricted use, distribution, and reproduction in any medium or format, provided the original work is correctly cited. 


\section{Case description}

A 74-year-old woman presented in the emergency department with left hemiparesis Medical Research Council (MRC) Grade 4, noticed upon her awakening. Her initial National Institutes of Health Stroke Scale (NIHSS) score was 4. The past medical history included congestive heart failure, poorly controlled diabetes with end-organ lesion, well-controlled hypertension, dyslipidemia, and obesity. Initial head computed tomography (CT) scan revealed right external capsular hemorrhage with a diameter of $12 \mathrm{~mm}$. Magnetic resonance imaging (MRI) also showed a lesion in the right parieto-occipital region (compatible with a previous asymptomatic ischemic event), vascular leukoencephalopathy, and multiple (>10) subcortical hypointense lesions in T2-weighted images compatible with strictly lobar microbleeds. No cortical siderosis was observed. These findings, according to the modified Boston Criteria for cerebral amyloid angiopathy (CAA), indicate the diagnosis of probable CAA [1] (Figure 1). Also, the thoraco-abdominopelvic CT-scan showed no potential neoplastic lesion; however, it led to the discovery of a left intraventricular thrombus. An echocardiogram revealed a dilated left ventricle with akinesia of the posterior and inferior wall and an ejection fraction of $23 \%$. The laboratory investigation of two different blood samples showed elevated activated partial thromboplastin time (aPTT), being likewise positive for lupus anticoagulant. Nevertheless, it is highlighted that the samples were withdrawn within less than 12 weeks of interval. Other relevant clinical observations showed a hemoglobin A1c (HbA1c) level of $6.8 \%$ and a low-density lipoprotein level of $102 \mathrm{mg} / \mathrm{dL}$. These findings suggested the diagnosis of antiphospholipid syndrome (APS), although not completely fulfilling the revised classification criteria for definite APS [2]. Due to hemorrhagic risk, the patient was not given anticoagulants and was discharged with an antiplatelet agent only. One month later, the patient reported a transient episode of slurred speech compatible with a transient ischemic attack (TIA). Two months after the primary episode, the patient recurred to the emergency department with left hemiparesis, left homonymous hemianopia, and left visuospatial neglect. CT scan showed early signs of ischemic stroke in the left middle cerebral artery territory. Because of elevated risk, the patient was not subjected to thrombolysis, and she later died of stroke-related complications one and a half months later.
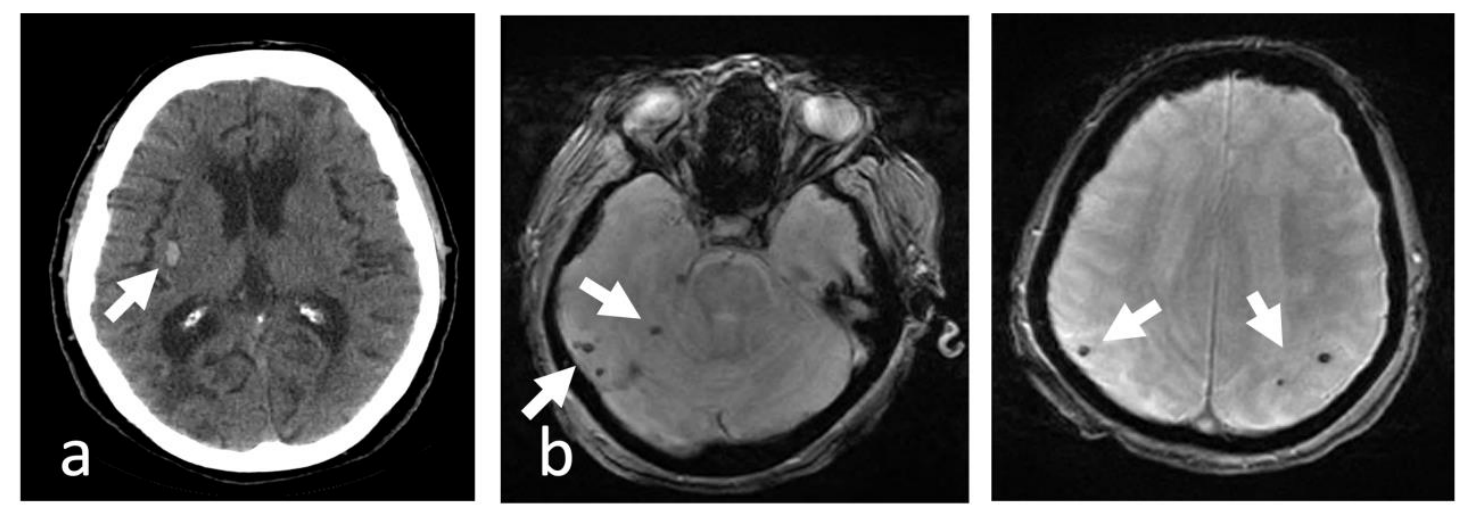

Figure 1 a) Head CT scan showing right external capsular hemorrhage with 12 millimeters of diameter; b) head MRI with T2-weighted images showing multiple hypointense lesions compatible with cerebral microbleeds. 


\section{Discussion}

In our patient, the factors in favor and against the use of oral anticoagulation (OAC) are several and are of different nature. The use of OAC therapy should be considered for patients with APS and previous stroke or TIA, depending on the risk of bleeding events [3]. Only vitamin K antagonists (VKA) have demonstrated efficacy in this context [4]. Also, several studies have been conducted about the potential benefit of OAC in patients with heart failure and sinus rhythm, particularly those with an ejection fraction of $<35 \%$, as is the case of our patient. Despite an overall reduction of non-fatal ischemic stroke with the use of OAC, compared with the use of antiplatelet agents, the number of major hemorrhagic events increased, and overall mortality showed an insignificant reduction. Hence, heart failure, in itself, may not indicate OAC [5]. However, OAC is used in the presence of an intracardiac thrombus, even if only temporarily, to achieve thrombus resolution. Despite this indication solely based on expert opinions, it is regarded as consensual [6].

On the other side, CAA is associated with a higher risk of ischemic stroke (IS) and intracerebral hemorrhage $(\mathrm{ICH})$. Further, even though both risks increase with the number of cerebral microbleeds $(\mathrm{CMB})$, the relative risk increase of $\mathrm{ICH}$ is steeper than that of IS, especially if the number of $\mathrm{CMB}$ is $\geq 5$. These data and the fact that the relative risk of $\mathrm{ICH}$ increases proportionately to $\mathrm{CMB}$ suggest a greater risk of $\mathrm{ICH}$ in some of the patients than that of IS [7]. Also, a recent metaanalysis showed that OAC markedly increases the risk of $\mathrm{ICH}$ in patients with previous ischemic stroke and $\geq 5 \mathrm{CMB}$ of any etiology, being the risk of $\mathrm{ICH}$ of $2.8 \%$ per year. This risk and the fact that warfarin-related $\mathrm{ICH}$ has a more devastating outcome suggest that in patients with a higher risk of IS, the harm of OAC could be greater than the benefit [8]. A previous sensitivity analysis showed that, in patients with previous deep ICH, a Vitamin $\mathrm{K}$ antagonist (VKA) could be beneficial if the risk of IS is notably high [9]. However, this is not true for our patient, as the CAA-related ICH recurrence risk is 7-fold higher than non-CAA-related ICH [10]. A prospective study showed that VKAs are associated with an increase in CMB number, but non-vitamin $\mathrm{K}$ antagonist OACS (NOAC) are not, leading to the hypothesis that NOAC therapy does not further aggravate cerebral small vessel disease [11]. Moreover, VKA use is associated with a higher incidence and a worse clinical outcome of ICH than NOAC use [12]. A recent pooled evaluation of several cohort studies on patients with previous IS or TIA and CMBs showed that even though the relative risk of $\mathrm{ICH}$ grows steeper than that of IS per additional CMB, the absolute risk of IS remains remarkably higher than that of ICH. This happens regardless of the antithrombotic treatment (oral anticoagulation or antiplatelet therapy) or CMB pattern. However, this study did not include patients with previous ICH and did not consider the mortality rate or the degree of morbidity caused by different events [13]. A previous prospective cohort study showed that patients with previous $\mathrm{ICH}$ and lobar microbleeds have probably a higher risk for future ICH (7.1-11\% per year) than lobar microbleed-only patients [14].

This case report throws us a challenge of whether antiplatelet use can augment the risk of ICH in CAA patients, as seems likely in our case. However, the magnitude of the increased risk in comparison to OAC use remains unexplored [15]. Previous studies suggest a similarity in ICH risk between patients under anticoagulation and antiplatelet therapy; however, they do not refer to the effect of these therapies in previous ICH or CAA patients $[16,17]$. 


\section{Conclusion}

The current case report revealed no clear case for or against OAC use, even of short duration in the patient in our hospital. However, an off-the-label NOAC could have been considered, especially after the episode of TIA, as some studies have indicated that VKA use can be harmful in these patients, but little is known in the case of NOAC use. Ultimately, OAC use should be contemplated after IS and ICH risk assessment based on the clinician's evaluation, as these cases may remain too rare to undertake a potential clinical trial.

\section{Abbreviations:}

aPTT - activated partial thromboplastin time; aPS - antiphospholipid syndrome; CAA - cerebral amyloid angiopathy; $\mathrm{CMB}$ - cerebral microbleeds; ICH - intracerebral haemorrhage; NOAC - nonvitamin $\mathrm{K}$ antagonist OACs; OAC - oral anticoagulation; TIA - transient ischemic attack; VKA - vitamin K antagonists

\section{Author Contributions}

Axel Ferreira, MD - Drafted the manuscript for intellectual content; Filipa Guimarães, MD - Revised the manuscript for intellectual content; Paulo Simões Coelho, MD - Revised the manuscript for intellectual content

\section{Competing Interests}

The authors have declared that no competing interests exist.

\section{References}

1. Linn J, Halpin A, Demaerel P, Ruhland J, Giese AD, Dichgans M, et al. Prevalence of superficial siderosis in patients with cerebral amyloid angiopathy. Neurology. 2010; 74: 1346-1350.

2. Miyakis S, Lockshin MD, Atsumi T, Branch DW, Brey RL, Cervera RH, et al. International consensus statement on an update of the classification criteria for definite antiphospholipid syndrome (APS). J Thromb Haemost. 2006; 4: 295-306.

3. Kernan WN, Ovbiagele B, Black HR, Bravata DM, Chimowitz MI, Ezekowitz MD, et al. Guidelines for the prevention of stroke in patients with stroke and transient ischemic attack: A guideline for healthcare professionals from the American Heart Association/American Stroke Association. Stroke. 2014; 45: 2160-2236.

4. Cohen $\mathrm{H}$, Efthymiou $\mathrm{M}$, Isenberg DA. Use of direct oral anticoagulants in antiphospholipid syndrome. J Thromb Haemost. 2018; 16: 1028-1039.

5. Beggs SA, Rorth R, Gardner RS, McMurray JJ. Anticoagulation therapy in heart failure and sinus rhythm: A systematic review and meta-analysis. Heart. 2019; 105: 1325-1334.

6. Habash F, Vallurupalli S. Challenges in management of left ventricular thrombus. Ther Adv Cardiovasc Dis. 2017; 11: 203-213.

7. Wilson D, Charidimou A, Ambler G, Fox ZV, Gregoire S, Rayson P, et al. Recurrent stroke risk and cerebral microbleed burden in ischemic stroke and TIA: A meta-analysis. Neurology. 2016; 87: 1501-1510. 
8. Charidimou A, Karayiannis C, Song TJ, Orken DN, Thijs V, Lemmens R, et al. Brain microbleeds, anticoagulation, and hemorrhage risk: Meta-analysis in stroke patients with AF. Neurology. 2017; 89: 2317-2326.

9. Eckman MH, Rosand J, Knudsen KA, Singer DE, Greenberg SM. Can patients be anticoagulated after intracerebral hemorrhage? A decision analysis. Stroke. 2003; 34: 1710-1716.

10. Charidimou A, Imaizumi T, Moulin S, Biffi A, Samarasekera N, Yakushiji Y, et al. Brain hemorrhage recurrence, small vessel disease type, and cerebral microbleeds: A meta-analysis. Neurology. 2017; 89: 820-829.

11. Saito T, Kawamura Y, Sato N, Kano K, Takahashi K, Asanome A, et al. Non-vitamin k antagonist oral anticoagulants do not increase cerebral microbleeds. J Stroke Cerebrovasc Dis. 2015; 24: 1373-1377.

12. An SJ, Kim TJ, Yoon BW. Epidemiology, Risk factors, and clinical features of intracerebral hemorrhage: An update. J Stroke. 2017; 19: 3.

13. Wilson D, Ambler G, Lee KJ, Lim JS, Shiozawa M, Koga M, et al. Cerebral microbleeds and stroke risk after ischaemic stroke or transient ischaemic attack: A pooled analysis of individual patient data from cohort studies. Lancet Neurol. 2019; 18: 653-665.

14. van Etten ES, Auriel E, Haley KE, Ayres AM, Vashkevich A, Schwab KM, et al. Incidence of symptomatic hemorrhage in patients with lobar microbleeds. Stroke. 2014; 45: 2280-2285.

15. Biffi A, Halpin A, Towfighi A, Gilson A, Busl K, Rost N, et al. Aspirin and recurrent intracerebral hemorrhage in cerebral amyloid angiopathy. Neurology. 2010; 75: 693-698.

16. Connolly SJ, Eikelboom J, Joyner C, Diener HC, Hart R, Golitsyn S, et al. Apixaban in patients with atrial fibrillation. N Engl J Med. 2011; 364: 806-817.

17. Diener HC, Sacco RL, Easton JD, Granger CB, Bernstein RA, Uchiyama S, et al. Dabigatran for prevention of stroke after embolic stroke of undetermined source. N Engl J Med. 2019; 380: 1906-1917.

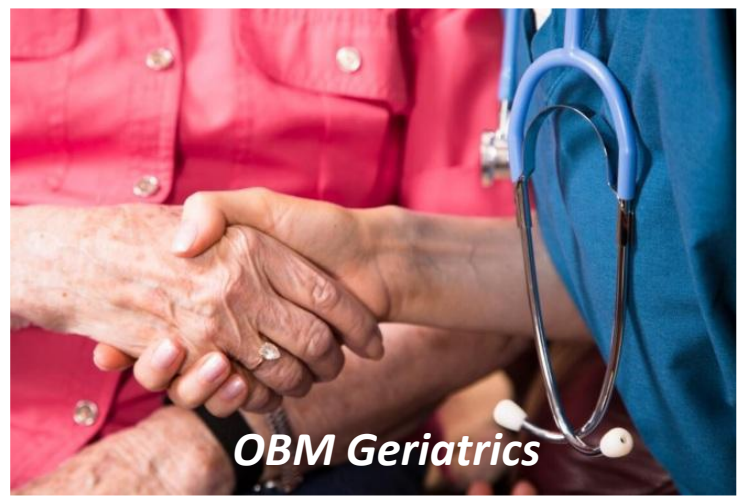

Enjoy $O B M$ Geriatrics by:

1. Submitting a manuscript

2. Joining in volunteer reviewer bank

3. Joining Editorial Board

4. Guest editing a special issue

For more details, please visit: http://www.lidsen.com/journals/geriatrics 